\title{
DIAGNOSTIC VALUE OF JAK2 V617F MUTATIONAL SCREENING IN PATIENTS WITH BUDD-CHIARI SYNDROME
}

\author{
Iman Mohamed Amin Omar, Mona FatheyAbd Elfattah, Noha Bassiouny \\ Hassan Mostafa and Esraa Mansour Shehata A
}

${ }^{1}$ Clinical Pathology

Department, Faculty of

Medicine, Ain Shams

University, Cairo, Egypt.

.Corresponding :

Esraa Mansour Shehata

Mobile: 01007042328

E mail:

esraamansour144@gmail.com

Received: 19/5/2019

Accepted: 12/6/2019

\begin{abstract}
:
Background: The diagnosis of underlying myeloproliferative neoplasms (MPNs) is often problematic in patients with Budd Chiari syndrome (BCS). A clonal mutation in JAK2 tyrosine kinase (JAK2V617F) occurs in a high proportion of patients with MPNs and is of use in the characterization of occult MPNs in BCS.
\end{abstract}

Aim of the work: Detection of JAK2 V617F mutation in patients with BCS and its value in detection of occult MPNs.

Patients and Methods: This study was carried out on fifty seven newly diagnosed Budd Chiari syndrome patientswho were attending tropical department in Ain Shams University Hospitals during the period from July 2017 to July 2018.Detection of JAK2V617F mutation was done by real time polymerase chain reaction.

Results: Out of the studied 57 BCS patients, JAK2 V617F mutation was detected in 12 patients (21.1\%) $\{10$ (83.3\%) were heterozygous and 2(16.7\%) were homozygous for mutation\}, while 45 patients (78.9\%) were negative.On comparing JAK2 V617F positive and negative groups, there was a highly statistically significant relation regarding MPNs diagnosis, where all JAK2 V617F positive patients were diagnosed as MPNs of whom 7 (58.3\%) had overt presentation and $5(41.7 \%)$ had occult presentation, while in JAK2 V617F negative patients only 2 were diagnosed overt MPNs $(p=0.001)$.

Conclusion: In conclusion the JAK2 V617F mutation is an acquired mutation that can be used for diagnosis of latent MPNs presenting with thrombotic events, thus it is recommended to include JAK2 V617F gene analysis in the research panel for BCS patients.

Keywords: JAK2 V617Fmutation, Budd Chiari Syndrome, Real Time PCR, Myeloproliferative Neoplasms.

\section{INTRODUCTION}

Budd-Chiari syndrome is a lifethreatening group of disorders that result from obstruction of hepatic venous outflow, that may occur at the level of the hepatic venules (hepatic veno-occlusive disease), the large hepatic veins, inferior vena cava (IVC), or the right atrium (congestive hepatopathy $)^{[1]}$. BCSare relatively rare disorders; however, can be fatal if the underlying etiological factors are not diagnosed and treated ${ }^{[2]}$.

Etiological factors in a significant proportion of BCS cases include: thrombophilic abnormalities and clonal disorders of hematopoiesis, such as Philadelphia chromosome negative myeloproliferative neoplasms both overt and occult ${ }^{[2]}$. The distinction between these two pathogenic mechanisms may have important clinical 
implications due to different treatment modalities ${ }^{[3]}$.

The diagnosis of MPNs in patients with BCS is often difficult at the time of acute thrombosis, as well as during the post thrombotic period. Some factors e.g. hemodilution, occult bleeding, and hypersplenism due to portal hypertension may obscure changes in blood cell counts used for diagnosing MPNs ${ }^{[4]}$.

Janus kinase 2 (JAK2) is a cytoplasmic tyrosine kinase that transduces signals triggered by hematopoietic growth factors such as erythropoietin in normal and neoplastic cells. The acquired gene mutation on chromosome 9 (JAK2 V617F) is associated with polycythemia vera and other related MPNs ${ }^{[2]}$

JAK2 V617F-positive MPNs are one of the most frequent thrombotic conditions underlying a diagnosis of BCS ${ }^{[5]}$. Therefore, to screen for JAK2 V617F mutation in patients with BCS is considered a valuable method for diagnosing occult MPNs presenting with thrombotic events ${ }^{[2]}$

\section{AIM OF THE WORK:}

This study aims at detection of JAK2 V617F mutation in patients with BCS and its value in detection of occult MPNs.

\section{SUBJECTS AND METHODS:}

\section{Study Subjects:}

The present study was carried out on fifty seven newly diagnosed Budd Chiari syndrome patients who were attending tropical department in Ain Shams University Hospitals during the period from July 2017 to July 2018. Verbal informed consent was obtained from all patients.

- To reach diagnosis and classification, all patients were subjected to the following:

A. Complete history taking stressing on transient risk factors for venous thromboembolism (including surgery, pregnancy, puerperium, oral contraceptive use, hormone replacement therapy, trauma, malignancy, prolonged immobilization (>10 days), and extensive travel ( $>8$ hours) in addition to thorough clinical examination.

B. Color Doppler ultrasound for the evaluation of the IVC, and hepatic vein.

C. Laboratory investigations which include:

- Complete blood picture using Coulter LH 750 analyzer (coulter electronics, Hialeah, FL, USA).

- Prothrombin time (PT), INR and activated partial thromboplastin time (APTT) using Stago Compact analyzer (Germany).

- Thrombophilia screening tests: prothrombin G20210A mutation, methyl tetrahydrofolatereductase (MTHFR) mutation, Factor V Leiden mutation, serum level of antithrombin, protein $\mathrm{C}$, protein $\mathrm{S}$, and antiphospholipid antibodies (lupus anticoagulant and anticardiolipin). The screening tests results were obtained from patient files.

- Investigations for presence of any associated Philadelphia negative MPNs according to WHO 2016 diagnostic criteria $^{[6]}$

- Detection of JAK2V617F mutation by real time polymerase chain reaction (RT-PCR) using Slan 96P real time PCR system (SANSURE BIOTECH INC, China) using ipsogen JAK2 Muta Screen Kit (catalog no. 673022).

\section{Methods:}

Detection JAK2V617F mutation by (real time PCR): all samples were analysed for JAK2V617F mutation by real time polymerase chain reaction ) using Slan 96P Real Time PCR System (SANSURE BIOTECH INC, China) using ipsogen JAK2 
Muta Screen Kitafter DNA extractionfrom fresh PB samples with QIAampDNA mini kit (Qiagen, Germany) according to manufacturer's spin protocol.

\section{Statistical analysis:}

All data were analyzed using SPSS Version 20.0. (Armonk, NY: IBM Corp). Data are expressed as mean \pm standard deviation (SD) or frequency and percentage as appropriate. Differences in discrete variables between groups were evaluated using the chi-square, student $t$ or fishers exact tests according to sample size.

\section{RESULTS}

\section{Demographic and Clinical data (Table 1):}

Out of 57 BCS patients; 23(40.4\%) were males and 34(59.6\%) were females with male to female ratio 1: 1.4 . Their ages ranged from 13 to 55 with mean of $27.9 \pm 8$ years. One $(1.8 \%)$ patient presented with isolated splenomegaly, $12(21.1 \%)$ with isolated hepatomegaly, while $36(63.2 \%)$ with combined hepatosplenomegaly. Seven $(12.3 \%)$ had history of thrombosis at sites other than hepatic veins and $9(15.8 \%)$ had history of oral/ genital ulcers.According to clinical presentation; $36(63.2 \%)$ had chronic onset while $11(19.3 \%)$ and $10(17.5 \%)$ had sub-acute and acute onset respectively.

Table (1): Description of demographic and clinical data

SD: standard deviation.

\begin{tabular}{|c|c|c|}
\hline \multicolumn{2}{|l|}{ Parameter } & Range $[($ Mean \pm SD $)$ \\
\hline \multicolumn{2}{|l|}{ Age (years) } & $13-55(27.91 \pm 8.13)$ \\
\hline \multicolumn{2}{|l|}{ Parameter } & Number $(\%)$ \\
\hline \multirow[t]{3}{*}{ Sex } & Male & $23(40.4 \%)$ \\
\hline & Female & $34(59.6 \%)$ \\
\hline & Male:Female ratio & $1: 1.4$ \\
\hline \multirow[t]{3}{*}{ Organomegaly } & Hepatomegaly & $12(21.1 \%)$ \\
\hline & Splenomegaly & $1(1.8 \%)$ \\
\hline & Hepatosplenomegaly & $36(63.1 \%)$ \\
\hline \multirow[t]{2}{*}{ History } & Thrombosis in other sites & $7(12.3 \%)$ \\
\hline & Oral/Genital ulcer & $9(15.8 \%)$ \\
\hline \multirow[t]{3}{*}{ Clinical presentation } & Acute & $10(17.5 \%)$ \\
\hline & Sub-acute & $11(19.3 \%)$ \\
\hline & Chronic & $36(63.2 \%)$ \\
\hline
\end{tabular}

\section{Laboratory and Radiological data (Table 2)}

Regarding laboratory data, complete blood picture (CBC) parameters showed hemoglobin concentration ranged from (717) $\mathrm{g} / \mathrm{dL}$ with mean value of $12.24 \pm 2.40$ $\mathrm{g} / \mathrm{dL}$, total leucocytic count ranged from (1.60-26) $\times 10^{9} / \mathrm{L}$ with median of 7.3(IQR: 5$10.9) \times 10^{9} / \mathrm{L}$ and the platelet count ranged from $(37-909) \times 10^{9} / \mathrm{L}$ with mean value of $234.60 \pm 189.52 \times 10^{9} / \mathrm{L}$.
Coagulation profile showed PT ranged from 11-34 seconds with mean value of $14.36 \pm 3.84$, INR ranged from $0.90-2.50$ with mean value of $1.28 \pm 0.34$ and APTT ranged from $26-65$ seconds with mean value of $30.49 \pm 8.68$.

Concerning the site of thrombosis; 48 (84.2\%) had MHV thrombosis, 52(91.2\%) had LHV thrombosis and 50(87.7\%) had RHV thrombosis, while 9 (15.8\%) had associated IVC thrombosis and $2(3.5 \%)$ had associated PV thrombosis. 
Iman Mohamed Amin Omar, et.al.,

Table (2): Description of site of thrombosis and laboratory data

\begin{tabular}{|c|c|c|}
\hline \multicolumn{2}{|l|}{ Parameter } & $\begin{array}{l}\text { Range }[(\text { Mean } \pm \text { SD) or } \\
\text { (Median IOR)* }\end{array}$ \\
\hline \multirow[t]{3}{*}{ CBC parmeters } & $\mathrm{Hb}(\mathrm{g} / \mathrm{dL})$ & $7-17(12.24 \pm 2.4)$ \\
\hline & $\mathrm{TLC}\left(\times 10^{9} / \mathrm{L}\right)$ & $1.6-26[7.3(5-10.9) *]$ \\
\hline & Platelets $\left(\times 10^{9} / \mathrm{L}\right)$ & $37-909(234.6 \pm 189.52)$ \\
\hline \multirow{3}{*}{$\begin{array}{l}\text { Coagulation } \\
\text { profile }\end{array}$} & PT (seconds) & $11-34(14.36 \pm 3.84)$ \\
\hline & INR & $0.90-2.50(1.28 \pm 0.34)$ \\
\hline & APTT (seconds) & $26-65(30.49 \pm 8.68)$ \\
\hline \multirow{5}{*}{$\begin{array}{lr}\text { Location } & \text { of } \\
\text { thrombosis by } \\
\text { doppler Ultra } \\
\text { sound }\end{array}$} & MHV thrombosis & $48(84.2 \%)$ \\
\hline & RHV thrombosis & $50(87.7 \%)$ \\
\hline & L HV thrombosis & $52(91.2 \%)$ \\
\hline & PV thrombosis & $2(3.5 \%)$ \\
\hline & IVC thrombosis & $9(15.8 \%)$ \\
\hline
\end{tabular}

SD: standard deviation, IQR: inter quartile range, CBC: complete blood picture, Hb: hemoglobin, TLC: total leucocytic count, PT: prothrombin time, INR: international normalized ratio, APTT: activated partial thromboblastin time, MHV: main hepatic vein, RHV: righ hepatic vein, LHV: left hepatic vein, PV: portal vein, IVC: inferior vena cava.

Etiological factors of Budd Chiari factor V Lieden mutation detected in 17 Syndrome (Table 3) $(29.8 \%)$ patients $\{14 \quad(82.4 \%) \quad$ were

The studied patients were divided according to the etiology of intravascular thrombosis into two groups; 19/57(33.3\%) of idiopathic etiology (no evident secondary pro-thrombotic factor for thrombosis) and $38 / 57(66.7 \%)$ secondary to other prothrombotic factors. Secondary prothrombotic factors were found either single factor in $17 / 38(44.7 \%)$ or a combination of multiple secondary prothrombotic factors in $21 / 38(55.3 \%)$ of patient.

The most common secondary prothrombotic factor was methyl tetra hydropholatere- ductase (MTHFR) mutation, detected in 24 patients $(42.1 \%) \quad\{23(95.8 \%)$ were heterozygous and $1(4.2 \%)$ was homozygous for mutation\} followed by heterozygous and $3(17.6 \%)$ were homozygous for mutation $\}$, followed by MPNs diagnosed in 14 (24.6\%) patients; of whom $5(8.8 \%)$ were diagnosed as occult MPNs and $9(15.8 \%)$ were diagnosed as overt MPNs ( $\mathrm{PV}=5, \mathrm{ET}=4)$. Other secondary pro-thrombotic factors include Behcet disease which was diagnosed in $10(17.9 \%)$ patients, antiphospholipid syndrome was diagnosed in $8(14 \%)$ patients, pregnancy was found in $7(12.3 \%)$ patients, hormonal replacement therapy was taken in $5(8.8 \%)$ patients, protein $\mathrm{C}$ deficiency was found in 3 (5.3\%) patients, prothrombin G 20210A mutation detected in $2(3.5 \%)$ patients, while protein $\mathrm{S}$ deficiency was found in only one $(1.8 \%)$ patient. None of our patients had anti thrombin III deficiency or PNH. 
Table (3): Description of Etiological factors of Budd Chiari Syndrome

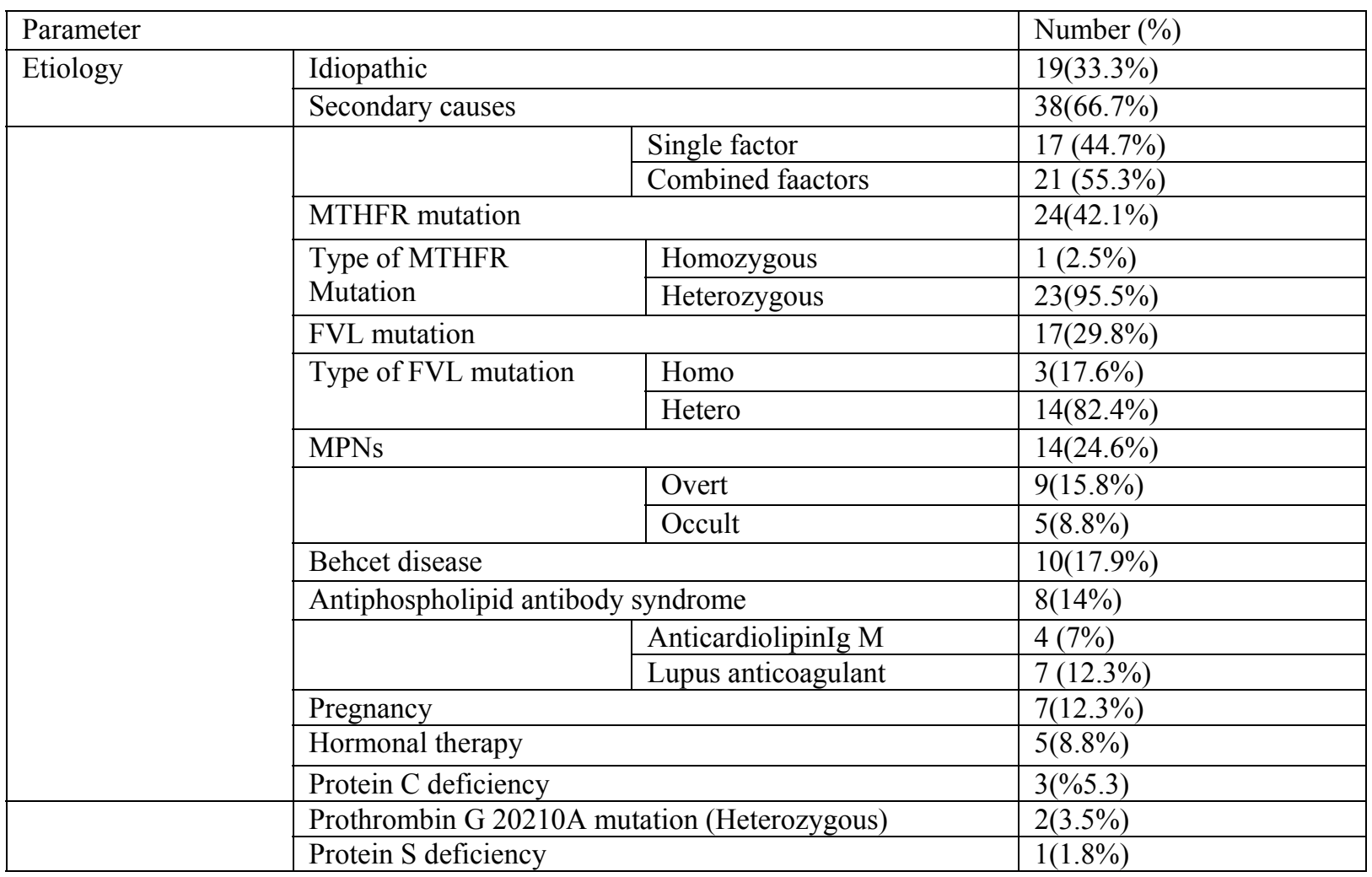

MPNs: myeloproliferative neoplasms, MTHFR: methyl tetrahydropholatereductase, FVL: factor v Leiden.

\section{JAK2 V617F mutational status in relation to etiology of BCS (Table 4)}

Out of 12 JAK2 V617F positive patients, 4 (33.3\%)had idiopathic etiology and $8(66.7 \%)$ patients had associated secondary pro-thrombotic factors while the 45 JAK2V617F negative patients $15(33.3 \%)$ had idiopathic etiology and $30(66.7 \%)$ had associated secondary pro-thrombotic factors.

Table (4): Comparison between negative and positive JAK2 V617F mutation cases as regard etiology of BCS

\begin{tabular}{|l|c|c|}
\hline & $\begin{array}{c}\text { JAK2 V617F Positive }(\mathrm{n}=12) \\
\text { Number }(\%)\end{array}$ & $\begin{array}{c}\text { JAK2 V617F Negative }(\mathrm{n}=45) \\
\text { Number }(\%)\end{array}$ \\
\hline Idiopathic cases $(\mathrm{n}=19)$ & $4(33.3 \%)$ & $15(33.3 \%)$ \\
\hline Secondary cases $(\mathrm{n}=38)$ & $8(66.7 \%)$ & $30(66.7 \%)$ \\
\hline
\end{tabular}

JAK2 V617F: janus kinase 2 V617F

JAK2 V617F mutational status in relation to secondary pro-thrombotic factors (Table 5)

On comparing JAK2 V617F positive and negative groups, there was a highly statistically significant relation regarding MPNs diagnosis, where all JAK2 V617F positive patients were diagnosed as MPNs of whom $7(58.3 \%)$ had overt presentation and $5(41.7 \%)$ had occult presentation, while in JAK2 V617F negative patients only 2 were diagnosed overt MPNs $(\mathrm{p}=0.001)$. No significant association was found on comparing both groups regarding other secondary pro-thrombotic factors. 
Table (5): Comparison between negative and positive JAK2 V617F mutation cases as regard secondary pro-thrombotic factors

\begin{tabular}{|l|l|c|c|c|c|}
\hline \multicolumn{2}{|c|}{ Parameter } & $\begin{array}{c}\text { JAK2 V617F } \\
\text { positive (n=12) } \\
\text { Number (\%) }\end{array}$ & $\begin{array}{c}\text { JAK2 V617F } \\
\text { negative (n=45) } \\
\text { (Number (\%) }\end{array}$ & $\begin{array}{c}\text { P } \\
\text { Value }\end{array}$ & Sig \\
\hline \multirow{4}{*}{$\begin{array}{l}\text { Secondary } \\
\text { Causes }\end{array}$} & Protein C deficiency & $1(8.3 \%)$ & $2(4.4 \%)$ & $0.51^{* *}$ & NS \\
\cline { 2 - 6 } & Protein S deficiency & $0(0.0 \%)$ & $1(2.2 \%)$ & $1.0^{* *}$ & NS \\
\cline { 2 - 6 } & MPNs & $12(100 \%)$ & $2(4.4 \%)$ & $0.001^{* *}$ & HS \\
\cline { 2 - 6 } & Type of MPNs & $7(58.3)$ & $2(4.4 \%)$ & & \\
\cline { 2 - 6 } & Overt & $5(41.7)$ & $0(0 \%)$ & & \\
\cline { 2 - 6 } & FVL mutation & $2(\% 16.7)$ & $15(33.3 \%)$ & $0.31^{* *}$ & NS \\
\cline { 2 - 6 } & $\begin{array}{l}\text { Prothrombin G 20210A } \\
\text { mutation }\end{array}$ & $0(0 \%)$ & $2(4.4 \%)$ & 1.0 & NS \\
\cline { 2 - 6 } & MTHFR mutation & $4(33.3 \%)$ & $20(44.4 \%)$ & $0.489^{*}$ & NS \\
\cline { 2 - 6 } & $\begin{array}{l}\text { Antiphospholipid antibody } \\
\text { syndrome }\end{array}$ & $2(16.7 \%)$ & $6(13.3 \%)$ & $0.670^{* *}$ & NS \\
\cline { 2 - 6 } & Behcet disease & $2(16.7 \%)$ & $8(18.2 \%)$ & $1.0^{* *}$ & NS \\
\cline { 2 - 6 } & Hormonal therapy & $7(8.3 \%)$ & $4(8.9 \%)$ & $1.0^{* *}$ & NS \\
\cline { 2 - 6 } & Pregnancy & $7(15.6 \%)$ & $0(0.0 \%)$ & $0.32^{* *}$ & NS \\
\hline
\end{tabular}

JAK2 V617F: janus kinase 2 V617F, MPNs: myeloproliferative neoplasms, MTHFR: methyl tetrahydropholatereductase, FVL: factor v leiden, NS: non-significant, HS highly significant, ${ }^{*}$ Student $t$ test, $* *$ Fisher exact test, sig: significance

\section{Occult versus overt MPNs cases (Table 6)}

MPNs were diagnosed in 14 patients (24.6\%); of whom $5(8.8 \%)$ were diagnosed as occult MPNs and 9(15.8\%) were diagnosed as overt MPNs ( $\mathrm{PV}=5, \mathrm{ET}=4)$. All occult MPNs patients showed JAK2 V617F mutation 5(100\%), while in overt MPNs patients, JAK2 V617F mutation was detected in $7(77.8 \%)$ and the remaining 2 patients $(22.2 \%)$ had wild type JAK2 V617F (the diagnosis depended on other WHO 2016 criteria For PV and ET).

As regard $\mathrm{CBC}$ parameters, mean hemoglobin, TLC and platelets were higher in overt cases than occult cases, and overt cases are more associated with secondary pro-thrombotic risk factors.

Table (6):Comparison between occult and overt MPNs

\begin{tabular}{|c|c|c|c|}
\hline & & $\begin{array}{l}\text { overt cases }(\mathrm{n}=9) \\
(\text { Mean } \pm \text { SD) }\end{array}$ & $\begin{array}{l}\text { Occult cases }(\mathrm{n}=5) \\
(\text { Mean } \pm \text { SD })\end{array}$ \\
\hline \multicolumn{2}{|l|}{ Age (years) } & $27.4 \pm 7.1$ & $32.4 \pm 9.2$ \\
\hline \multicolumn{2}{|l|}{ Parameter } & Number (\%) & Number (\%) \\
\hline \multirow[t]{3}{*}{ Sex } & Male & $5(55.5 \%)$ & $2(40 \%)$ \\
\hline & Female & $4(44.4 \%)$ & $3(60 \%)$ \\
\hline & M: F ratio & $1.2: 1$ & $1: 1.5$ \\
\hline \multicolumn{2}{|l|}{ Parameter } & $($ Mean \pm SD) & $($ Mean \pm SD) \\
\hline \multirow[t]{3}{*}{ CBC parameters } & $\mathrm{Hb}(\mathrm{g} / \mathrm{dl})$ & $14.6 \pm 2.5$ & $11.42 \pm 2.3$ \\
\hline & $\mathrm{TLC}\left(\times 10^{9} / \mathrm{L}\right)$ & $12.1+6.3$ & $6.76 \pm 1.9$ \\
\hline & $\begin{array}{l}\text { Platelets } \\
\left(\times 10^{9} / \mathrm{L}\right)\end{array}$ & $545.6 \pm 266.9$ & $115.4 \pm 65.3$ \\
\hline \multirow{3}{*}{$\begin{array}{l}\text { Coagulation } \\
\text { profile }\end{array}$} & PT (seconds) & $14.6 \pm 3.9$ & $12 \pm 0.7$ \\
\hline & INR & $1.3+0.4$ & $1.08+0.1$ \\
\hline & $\begin{array}{l}\text { PTT } \\
\text { (seconds) }\end{array}$ & $32.9 \pm 12.7$ & $29.6 \pm 3.8$ \\
\hline \multicolumn{2}{|l|}{ Parameter } & Number (\%) & Number (\%) \\
\hline Etiology & Isolated & $3(33.3 \%)$ & $4(80 \%)$ \\
\hline
\end{tabular}




\begin{tabular}{|c|l|c|c|}
\hline & MPNs & $6(66.7 \%)$ & $1(20 \%)$ \\
\cline { 2 - 4 } & $\begin{array}{l}\text { Associated } \\
\text { secondary } \\
\text { cause }\end{array}$ & $7(77.8 \%)$ & $5(100 \%)$ \\
\hline $\begin{array}{c}\text { JAK2 V617F } \\
\text { Mutation }\end{array}$ & Positive & & \\
\hline
\end{tabular}

SD: standard deviation, CBC: complete blood picture, $\mathrm{Hb}$ : hemoglobin, TLC: total leucocytic count, PT: prothrombin time, INR: international normalized ratio, APTT: activated partial thromboblastintime, JAK2 V617F: janus kinase 2 V617F, MPNs: myeloproliferative neoplasms.

\section{DISCUSSION:}

Budd-chiari syndrome is a hepatic venous outflow tract obstruction. It could be primary from vein thrombosis or secondary from a compression or invasion of the vein as in malignancy ${ }^{[7]}$.

Thrombophilia abnormalities and clonal disorders of hematopoiesis such as Philadelphia chromosome negative MPNs are the two main mechanisms of intravascular thrombosis in a significant proportion of BCS. According to EL Sebay et al., ${ }^{[8]}$ BCS patients with MPN carry significant poorer prognostic features that need earlier hepatic decompression procedure.

Moreover the distinction between these two pathogenic mechanisms has important clinical implications because anticoagulants are the most rational treatment in cases of thrombophilia, whereas cytoreductive therapy is indicated in patients with MPNs [2]

The diagnosis of thrombophilia is relatively simple and accurate but the diagnosis of MPNs is often problematic in patients with BCS as hemodilution, occult bleeding, and hypersplenism due to portal hypertension may mask changes in blood cell counts used for diagnosing MPNs ${ }^{[9]}$.

Despite suggestive features of MPN in bone marrow, these patients lack adequate diagnostic criteria and are classified as occult MPNs ${ }^{[10]}$.
According to Karaköse et al., ${ }^{[2]}$ overt MPNs are observed in 23\%-31.2\% of patients with BCS which increases to $45 \%$ $53 \%$ when occult MPNs are included as an etiological factor.

In 2016 El Sebay and colleages suggested that testing JAK2 V617F should replace bone marrow examination as initial test for MPNs in BCS patients. Thus the aim of this work was to detect JAK2V617F mutation in patients with BCS and determine its value in detection of occult MPNs.

Our study involved 57 BCS patients divided according to the etiology of intravascular thrombosis into 2 groups, $19 / 57(33.3 \%)$ of idiopathic etiology and $38 / 57(66.7 \%)$ secondary to other prothrombotic factors.

In the present study JAK2 V617F mutation was positive in $12 / 57(21.1 \%)$ of the studied patients of whom $83.3 \%(10 / 12)$ were heterozygous and $16.7 \%(2 / 12)$ were homozygous for mutation. This is consistent with Helman et al., ${ }^{[5]}$ who identified JAK2 V617F mutation in 10/32 (31.2\%) of BCS patients and Sakr et al., ${ }^{[11]}$ who identified JAK2 V617F mutation in $18 / 62(29 \%)$ of BCS patients.

However in a study done by El Sebay et al., ${ }^{[12]}$, the frequency of JAK2 V617F mutation was lower as they identified 4/35 $(11.4 \%)$ of BCS patients all of them were of heterozygous for mutation. This difference may be attributed to using different method 
of detection (polymerase chain reactionrestriction fragment length polymorphism).

Also lower frequencies of JAK2 V617F mutation were reported by 2 different studies done by Chinese authorsWang et al., ${ }^{[13]}$ andQi et al., ${ }^{[14]}$ whoidentifiedJAK2 V617F mutation in $2.37 \%(7 / 295)$ and in $4.3 \%$ (4/92) respectively. Accordingly Wang et al., [13] stated that MPNs were uncommon risk factor for BCS in china.

In our study, JAK2V617F mutation was positive in $5 / 19(26.3 \%)$ of idiopathic BCS patients and in $7 / 37(18.4 \%)$ of secondary BCS patients. The idiopathic JAK2V617F positive patients were not diagnosed as overt MPNs (not fulfilling WHO 2016 diagnostic criteria), and could be considered as occult MPNs. Similarly, De Stefano et al., [15] reported JAK2V617F mutation in $33.3 \%$ of idiopathic BCS patients. Also, Karaköse et al., ${ }^{[2]}$ found the frequency ofJAK2 V617F mutation in $21.4 \%$ of patients with idiopathic BCS (all were considered occult MPNs) and in $17.6 \%$ of patients with secondary pro-thrombotic factors.

In our study, on comparing JAK2 V617F positive and negative patients, there was no statistically significant difference regarding associated inherited or acquired pro-thrombotic risk factors except for MPNs. The same was reported by Colaizzo et al., [16]. However, Karaköse et al., [2] reported additional pro-thrombotic factor that showed statistically significant association (FVL mutation), and this is in agreement withDenninger et al., ${ }^{[17]}$ who stated that the role of multiple factors in the etiology of thrombosis should not be ignored

In our study out of 12 JAK2V617F positive BCS patients, $5(41.7 \%)$ had occult presentation for MPNs and 7(58.3\%) had overt presentation However Yonal et al., ${ }^{[18]}$ identified out of 8 JAK2 V617F positive BCS patients $2(25 \%)$ with overt MPNs and $6(75 \%)$ with occult presentation for MPNs. Also Sakr et al., ${ }^{[11]}$ identified out of 18
JAK2 V617F positive BCS patients, $28.5 \%$ and $71.5 \%$ with overt and occult presentation for MPNS respectively.

In the current study, overt MPNs were diagnosed in $9(15.8 \%)$ patients of whom 7 $(77 \%)$ had JAK2 V617 mutation, and occult MPNs were diagnosed in $5(8.8 \%)$ patients, all of them (100\%) had JAK2 V617 mutation. Similarly, a study done by Karaköse et al., ${ }^{[2]}$ reported that overt MPNs were diagnosed in 8/111(7.2\%) patients, 4 of them had JAK2 V617F mutation and occult MPNs were diagnosed in 6/111(5.4\%) patients, all of them had JAK2 V617F mutation. This is also in agreement with Yonal et al., ${ }^{[18]}$ whoidentified overt MPNs in $3 / 19(15.8 \%)$ of BCS patients (2 of them were positive for JAK2 V617F mutation) and occult MPNs in 6/19 (31.6\%) all of them were positive for JAK2 V617F mutation.

Also, in our study overt cases showed mean hemoglobin, TLC and platelets higher than occult cases and this prove that hematological parameters are not reliable for diagnosis of occult MPNs

These results substantiate inclusion of JAK2V617F in the routine diagnostic work up of BCS patients regardless the absence of MPN hallmarks such as elevated peripheral blood count, as screening for the JAK2 V617 mutation is a valuable method for diagnosing occult MPNs.

\section{Conclusion:}

JAK2 V617F mutation is an acquired mutation used for the diagnosis of occult MPNs presenting with thrombotic events. Analysis of JAK2 mutations JAK2 gene analysis should be included in the research panel for BCS patients.

\section{REFERENCES}

1. Qi X., Han G., Guo X., De Stefano V., Xu K., Lu Z., et al (2016): Review article: the aetiology of primary Budd-Chiari 
syndrome-differences between the West and China. Alimentary pharmacology and therapeutics; 44(11): 1152-1167.

2. Karaköse S., Oruç N., Zengin M., Akarca US., and Ersöz G (2015): Diagnostic value of the JAK2 V617F mutation for latent chronic myeloproliferative disorders in patients with Budd-Chiari syndrome and/or portal vein thrombosis. Turkish Journal of Gastroenterology; 26:42-8.

3. Chait Y., Condat B., Cazals-Hatem D., Rufat P., Atmani, S., Chaoui D., et al (2005): Relevance of the criteria commonly used to diagnose myeloproliferative disorder in patients with splanchnic vein thrombosis. British journal of Haematology; 129(4): 553-560.

4. Murad SD., Valla DC., De Groen PC., Zeitoun G., Hopmans JA., Haagsma EB., et al (2004): Determinants of survival and the effect of portosystemic shunting in patients with Budd-Chiari syndrome. Hepatology; 39(2): 500-508.

5. Helman R., Pereira WDO., Marti LC., Campregher PV., Puga RD., Hamerschlak N., et al (2016): Granulocyte whole exome sequencing and endothelial JAK2V617F in patients with JAK2V617F positive BuddChiari Syndrome without myeloproliferative neoplasm. British Journal of Haematology; doi: 10.1111/bjh.14327.

6. Arber DA., Orazi A., Hasserjian R., Thiele J., Borowitz MJ., Le Beau MM., and Vardiman JW (2016): The 2016 revision to the World Health Organization classification of myeloid neoplasms and acute leukemia. Blood; 127(20): 2391-2405.

7. Valla DC (2017): Budd-Chiari syndrome/hepatic venous outflow tract obstruction. Hepatology International; 12 (1): 168-180.

8. El Sebay HM., Safan MA., Daoud AA., Tayel SI., A Nouh M., and El Shafie S (2016): Association of factor V Leiden, Janus kinase 2, prothrombin, and MTHFR mutations with primary Budd-Chiari syndrome in Egyptian patients. Journal of gastroenterology and hepatology; 31(1): 235-240.

9. Smalberg JH., Arends LR., Valla DC., Kiladjian JJ., Janssen HL. andLeebeek FW
(2012): Myeloproliferative neoplasms in Budd-Chiari syndrome and portal vein thrombosis: a meta-analysis. Blood; 120(25): 4921-4928.

10. Karam, D., Iyer V., and Agrawal B. (2017): Occult myeloproliferative neoplasms: not so occult any more. Case Reports; bcr-2017219388.

11. Sakr M., Barakat E., Abdelhakam S., Dabbous H., Yousuf S., Shaker M., and Eldorry A (2011): Epidemiological aspects of Budd-Chiari in Egyptian patients: a single-center study. World Journal of Gastroenterology; 17(42): 4704.

12. El Sebay HM., Safan MA., Daoud AA., Tayel SI., Nouh A., and El Shafie S (2017): Association of janus kinase 2 with primary Budd-Chiari syndrome in Egyptian patients. Menoufia Medical Journal; 30(4): 1044.

13. Wang H., Sun G., Zhang P., Zhang J., Gui E., Zu M., and Lu Z (2014): JAK 2 V 617 F mutation and 46/1 haplotype in $C$ hinese $B$ udd-C hiari syndrome patients. Journal of gastroenterology and hepatology; 29(1): 208-214.

14. Qi $\mathrm{X}$, Zhang $\mathrm{C}$, Han $\mathrm{G}$ etal. (2012): Prevalence of the JAK2V617F mutation in Chinese patients with Budd-Chiari syndrome and portal vein thrombosis: a prospective study. J. Gastroenterol. Hepatol; 27: 1036-1043.

15. De Stefano V, Fiorini A, Rossi E, et al. (2007): Incidence of the JAK2 V617F mutation among patients with splanchnic or cerebral venous thrombosis and without overt chronic myeloproliferative disorders. Journal of Thromb and Haemostasis; 5: 708-14.

16. Colaizzo D., Amitrano L., Tiscia GL., Scenna G., Grandone E., Guardascione MA., Brancaccio $\mathrm{V}$ and Margaglione $\mathrm{M}$. (2007): The JAK2 V617F mutation frequency occurs in patients with portal and mesenteric venous thrombosis. Journal of Thrombosis and Haemostasis; 5: 55-61.

17. Denninger $\mathrm{MH}$, Chaït $\mathrm{Y}$, Casadevall $\mathrm{N}$ et al., (2000): Cause of portal or hepatic venous thrombosis in adults: the role of multiple concurrent factors. Hepatology; 31: 587-91. 
18. Yonal I., Pinarbas1 B., Hindilerden F., Hancer V S., Nalcaci M., Kaymakoglu S., and Diz-Kucukkaya R (2012): The clinical significance of JAK2V617F mutation for Philadelphia-negative chronic myelopro- liferative neoplasms in patients with splanchnic vein thrombosis. Journal of thrombosis and thrombolysis; 34(3): 388396.

القيمه التشخيصيه لفحص طفره جانوس كيناز2 V617F في المرضى الذين يعانون من متلازمة بود كيارى

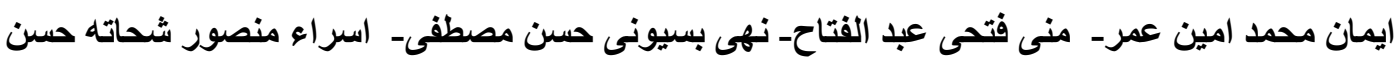

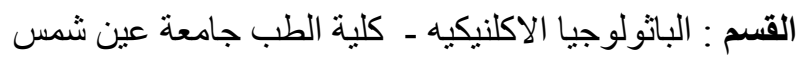

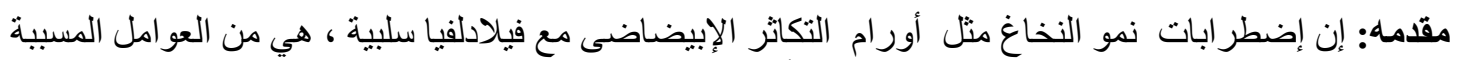

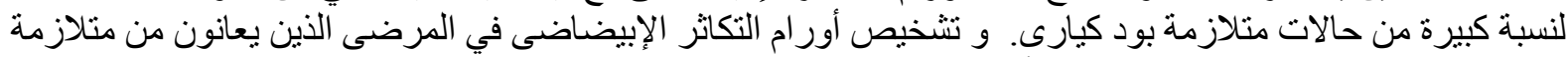

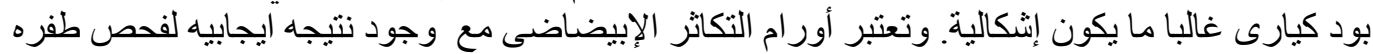

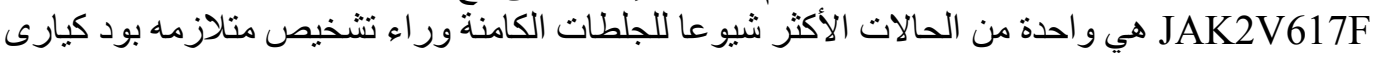

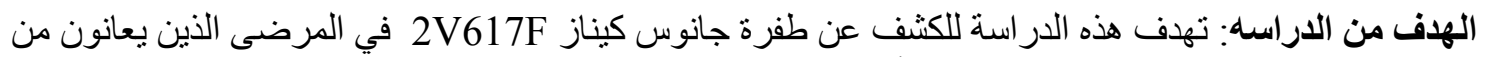

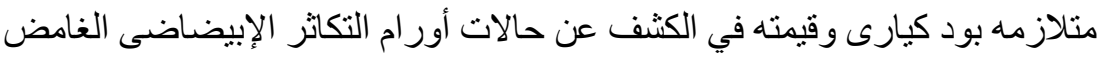

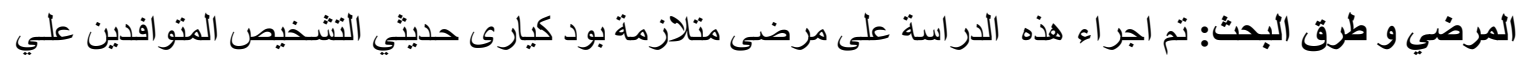

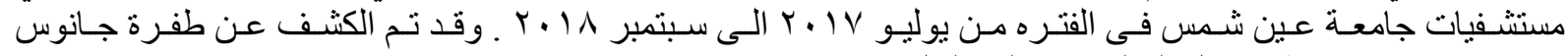
كيناز 2V617F بواسطة تفاعل البوليميريز الكنسلسل.

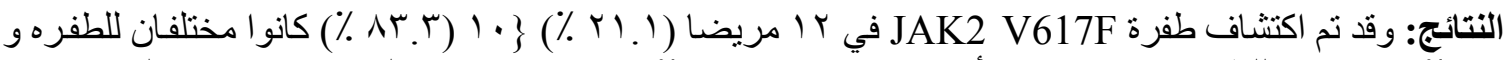

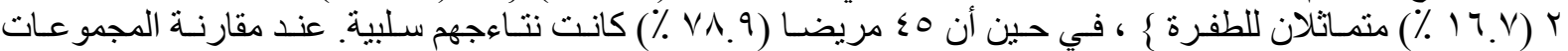

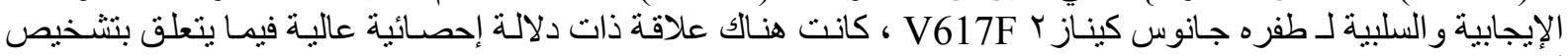

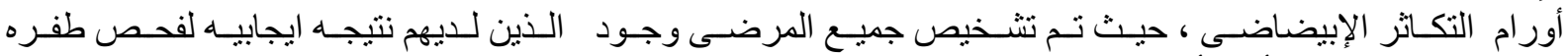

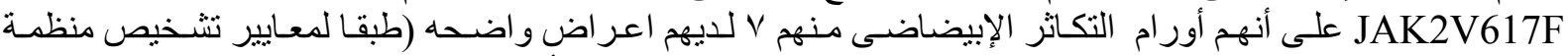

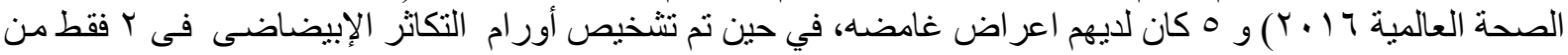

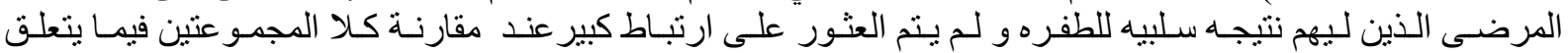

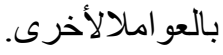

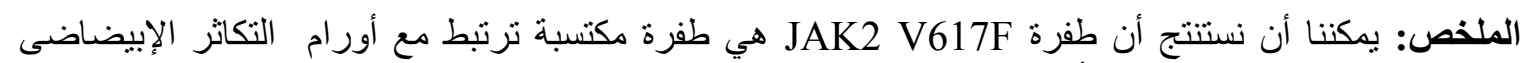

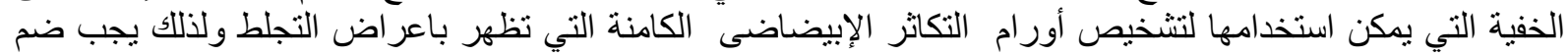
تحليل الجينات JAK2 في قائمه الفحوصات للمرضى الذين يعانون من متلازمه البود كيارى. 